\title{
Grasshopper Species-Area Relationship on Ungrazed and Overgrazed Grasslands*
}

\author{
KANG LE ZHANG MINGZHAO \\ Institute of Zoology, the Chinese Academy of Sciences, Beijing 100080 \\ (Received Narch 1, 1995; Revised April 23, 1995)
}

\section{ABSTRACT}

The species richness and abundance of rangeland grasshoppers were investigated at 6 sites of ungrazed and overgrazed pastures in Inner Mongolia during the autumn of 1994. The ungrazed sites supported higher richness and density of grasshoppers than the overgrazed sites. The effects of overgrazing and ungrazing on the species-area relationships of grasshoppers were directly measured. The grasshopper assemblages from the 6 sites differed significantly in the intercept or in the slopes of their species-area regressions. The greater intercept and slope values of their species-area regression were found in grasshopper assemblages on ungrazed sites. In contrast to species-area relationship regression, the species increase rate with individual number was more rapid at overgrazed sites. Implications for conservation are discussed.

Key zoords Grasshoppers, species-area relationship, grazing, grasslands

\section{Introduction}

The species-area relationship is the oldest and most general pattern in biogeography and comriunity by the power function (Preston 1962):

$$
S=C A^{Z}
$$

where $S$ is the number of species, $A$ is the area, and $C$ and $z$ are constants. The constants are estimated typically through linear regression on the logarithmic form of the equation (1):

$$
\log S=\log C+z \log A
$$

where $C$ represents the intercept, $z$ the slope. Primary interest in the species-area relationship has been to attach biological meaning to observed values of the intercept and slope (Connor and McCoy 1979, Gilbert 1980). This pattern, the species-area relationships or speciesarea curve, has been found in a wide variety of organism taxa and of communities (Connor and McCoy 1979). Recently, the relationship has been proposed as a model for optimal design of nature reserves (Terborgh 1974, Diamond and May 1976, Higgs 1981, Boecklen and Gotelii 1984, Usher 1985, Boecklen and Simberloff 1986). It has, in fact, been found so commonly that the species-area relationship has been referred to as one of community ecology's few genuine laws (Schoener 1976). The relationship between the number of species found in an area and the size of that area has been explained by three main hypotheses (Con-

* This study is supported by a special grant on biodiversity program entitled "Influences of Human Activities on the Ecosystem Diversity" from the Chinese Academy of Sciences 
nor and McCoy 1979). These are the passive sampling or random placement hypothesis (Arrhenius 1921, Coleman 1981, Connor and Mccoy 1979), the habitant diversity hypothesis (Williams 1964) and the equilibrium theory of island biogeography (MacArthur and Wilson 1967, Preston 1962).

Grasshoppers are considered to be important primary consumers in grassland ecosystems (Anderson 1964, Gryllenberg 1969, Samways 1993, Kang and Chen 1994). Grasshopper communities exhibit large temporal and spatial variation and oscillation in abundance. Some authors thought that grazing favours them (Holmes et al. 1979, Joern 1982, Kang 1994). Others, however, found that grazing had a negative effect (Capinera and Sechrist 1982, Barker 1982). Wingerden et al. (1991) pointed out that the effects depend on the intensity of gracing, while Welch et al. (1991) also referred to the time factor. There remain major gaps in our understanding of the effects of grazing on the species-area relationship of grasshoppers.

An analysis of the species-area of grasshoppers on overgrazed versus ungrazed grassland was conducted in the steppe region of Inner Mongolia in 1994. The main objective of this study was to examine the roles of the livestock grazing in determining the number of grasshopper species.

\section{$2 \quad$ Materials and methods}

\subsection{Study site}

The work reported here was done in the Inner Mongolian Grassland Ecosystem Research Station of Academia Sinica. The grassland region is situated at $43^{\circ} 26^{\prime}-44^{\circ} 08^{\prime} \mathrm{N}$ in latitude and $116^{\circ} 04^{\prime}-117^{\circ} 05^{\prime} \mathrm{E}$ in longitude. Specific details of the study area can be found elsewhere (Kang 1995, Kang and Chen 1994). Six sites were selected from the Anerolepidium chinense steppe and Stipa grandis steppe in this region. Sampling was conducted in the six sites; each site was approximately $100 \mathrm{hm}^{2}$ in area. The sites without the fence have been maintained at overgrazed intensity. The ungrazed sites were protected or restored by fence from grazing for over ten years. Originally they were selected because they exhibited uniform soil and vegetation types; however, through the years vegetation has shifted in response to overgrazing. The ungrazed and overgrazed sites that originally had same vegetation type are side by side, the fences are only bound between them.

\subsection{Grasshopper sampling}

Each grasshopper sampling required 3 days, and was performed in August and September of 1994. Grasshoppers were sampled by one $1 \mathrm{~m}^{2}$ cubical cage at each site for fifty samples $\left(50 \mathrm{~m}^{2}\right.$ in area in total). Five times of samplings were randomly conducted in each site, in different times during the day. Each sampling was conducted when the weather was warm, clear and calm. Grasshoppers collected were placed in plastic bottles containing $95 \%$ ethanol, and brought back to the laboratory for identification and counting.

\subsection{Data analysis}

The diversities represented by individual grasshopper assemblages were calculated both as species richness $(S)$ and as Shannon-Weaver measure $H^{\prime}$ :

$$
H^{\prime}=-\sum_{i}^{s} P_{i} \ln \left(P_{i}\right)
$$

where $P_{i}$ is the proportion of individuals belonging to species $i$. 
The interspecific covariation (Ludwig and Reynolds 1988) was conducted for analysis of grasshopper species-pair response to grazing. If the abundances of two species tend to increase and decrease together, they are responding in the same way to the same environmental factors. Pearson product-moment correlations and Spearman rank correlations were calculated for each species-pair of grasshoppers.

Relationship of grasshopper species-area was analyzed by the Equation (2). Analyses of covariance was determined if the grasshopper assemblages between ungrazed and overgrazed sites differed significantly in the intercept or in the slopes (The values of $z$ and $C$ in Equation 2) of their species-area regressions. The curves of species number and individual number were compared among sites.

\section{Results}

Twelve species of grasshoppers were collected on all study sites combined (Table 1 ). For the set of 6 sites, species richness $(S$ ) varies from 5 to 11 , and diversity indices from 0.91 to 1.23 . Greatest species richness $(S)$ and individual numbers of these grasshoppers occurred on the ungrazed sites. Greatest $H^{\prime}$ of these grasshoppers appeared on the overgrazed sites, although greatest $S$ occurred on the ungrazed sites. Therefore, the results of the greatest $S$ from these sites were not entirely consistent with the greatest $H^{\prime}$ value. The extreme values of $H^{\prime}$ were not the extreme values of species richness, but the overgrazed sites always maintained the lowest species richness.

Table 1 Grasshopper derisity (individuals $/ \mathrm{m}^{2}$ ), composition and diversity on the ungrazed and overgrazed grasslands

\begin{tabular}{lcccccc}
\hline \multicolumn{1}{c}{ Sites } & Anerolepidium & chinense steppe & \multicolumn{2}{c}{ An . chinense steppe } & \multicolumn{2}{c}{ Stipa grandis steppe } \\
\hline Grasshopper spp. & Overgrazed & Ungrazed & Degraded & Restored & Overgrazed & Ungrazed \\
\hline 1 Ch. fallax & 0.096 & 0.648 & 0.050 & 0.556 & 0.012 & 0.888 \\
2 C. abbreviatus & 0.024 & 0.068 & 0.140 & 0.432 & 0.096 & 0.603 \\
3 Ch. dubius & 0.220 & 0.040 & 0.340 & 0.124 & 0.204 & 0.040 \\
4 An. barabensis & 0.064 & 0.028 & 0.052 & 0.008 & 0.088 & 0.036 \\
5 O. haemorrboidalis & 0.016 & 0.028 & 0.004 & 0.008 & 0.000 & 0.032 \\
6 Brt. dilutum & 0.000 & 0.016 & 0.004 & 0.016 & 0.000 & 0.012 \\
7 O. d. asiaticus & 0.008 & 0.000 & 0.004 & 0.016 & 0.003 & 0.012 \\
8 D. barbipes & 0.000 & 0.032 & 0.016 & 0.004 & 0.000 & 0.000 \\
9 M. j. vittatus & 0.000 & 0.008 & 0.000 & 0.000 & 0.000 & 0.000 \\
10 Chrysacris sp. & 0.000 & 0.004 & 0.000 & 0.000 & 0.000 & 0.000 \\
11 P. m. meridionalis & 0.000 & 0.004 & 0.000 & 0.000 & 0.000 & 0.004 \\
12 Ch. brunneus & 0.004 & 0.008 & 0.012 & 0.004 & 0.000 & 0.000 \\
Total individuals & 108 & 221 & 156 & 316 & 102 & 406 \\
Species number & 7 & 11 & 8 & 8 & 5 & 7 \\
Diversity index ( H' ) & 1.2184 & 0.9749 & 1.2280 & 1.1498 & 1.0650 & 0.9110 \\
\hline
\end{tabular}

The Pearson and Spearman correlation coefficients were used to measure the grasshopper intensity of covariation in pairwise species abundance data. The results are summarized in Table 2. Of the 66 pairwise combinations, 17 correlations are significant using the Pearson correlation, but 20 with the Spearman rank correlation. A distinctive pattern of grasshopper species covariation is shown by the species covariation plexus diagram (Fig.1). The distance between species in a plexus diagram reflects their relative degree of positive covariation, that 
is, those that covary positively and significantly are displayed close together and those that negatively covary are displayed at a greater distance. For example, given pairwise interspecific covariations among 12 species, Figure 1 illustrates the grasshopper species might divide into 3 groups, which performed different response to livestock grazing. The grasshopper species with high number on overgrazed sites (e.g. An. barabensis, $O$. d. asiaticus and Ch. dubius) tend to covary negatively with grasshopper species with high number on ungrazed sites ( $\mathrm{Ch}$. fallax and $\mathrm{C}$. abbreviatus). Because there are double zero matches involved in grasshopper species, $M . j$. vittatus and Chrysacris sp., the correlation should be aware of the potential problem. In fact, these two species were more abundance on ungrazed and lightly grazed grasslands.

Table 2 Pearson (upper-right triangle) and Spearman (lower-left triangle) correlation coefficients for twelve species abundance of grasshoppers

\begin{tabular}{|c|c|c|c|c|c|c|c|c|c|c|c|c|}
\hline \multirow[b]{2}{*}{ SPP. } & \multicolumn{12}{|c|}{ Pearson product-moment correlations } \\
\hline & 1 & 2 & 3 & 4 & 5 & 6 & 7 & 8 & 9 & 10 & 11 & 12 \\
\hline 1 & 1.00 & $0.73^{*}$ & $-0.84^{* *}$ & $-0.81^{* *}$ & $-0.82^{*}$ & ${ }^{*} 0.86 * *$ & $-0.85^{*}$ & $* 0.40$ & 0.36 & 0.36 & $0.82 * *$ & -0.24 \\
\hline 2 & $\overline{0.37}$ & 1.00 & -0.46 & -0.40 & 0.37 & 0.55 & -0.53 & -0.29 & -0.33 & -0.33 & 0.36 & -0.42 \\
\hline 3 & $-0.81 *$ &.$\overline{0.32}$ & $\underline{1.00}$ & 0.49 & $-0.72 *$ & $-0.69^{*}$ & $-0.95^{*}$ & -0.52 & -0.49 & -0.49 & $-0.78^{*}$ & 0.53 \\
\hline 4 & $-0.89^{* *}$ & -0.31 & $\overline{0.75^{*}}$ & $\underline{1.00}$ & $-0.78^{*}$ & $-0.83^{*}$ & 0.52 & -0.59 & -0.57 & -0.57 & -0.75 & -0.36 \\
\hline 5 & $0.94^{* *}$ & 0.14 & $-0.70^{*}$ & $.0 .77 * *$ & 1.00 & 0.55 & .0 .65 & 0.45 & 0.50 & 0.50 & $0.91^{* *}$ & -0.14 \\
\hline 6 & $0.71^{*}$ & 0.41 & -0.67 & $-0.88^{* *}$ & $\overline{0.47}$ & 1.00 & $-0.78^{*}$ & ${ }^{*} 0.59$ & 0.52 & 0.52 & 0.61 & 0.09 \\
\hline 7 & $-0.83^{* *}$ & .0 .34 & $0.94^{* *}$ & $0.74^{*}$ & 0.68 & $-\overline{0.76}$ & 1.00 & -0.45 & -0.40 & -0.40 & -0.63 & 0.49 \\
\hline 8 & 0.44 & -0.10 & -0.57 & -0.68 & 0.27 & $0.84^{* *}$ & $-\overline{0.66}$ & 1.00 & $0.99^{* *}$ & $0.99^{* *}$ & 0.60 & 0.35 \\
\hline 9 & 0.39 & -0.39 & -0.53 & -0.66 & 0.39 & 0.54 & -0.42 & $\overline{0.76}^{*}$ & 1.00 & $1.00^{* *}$ & 0.63 & 0.35 \\
\hline 10 & 0.39 & -0.39 & -0.53 & -0.66 & 0.39 & 0.54 & -0.42 & $0.76^{*}$ & $\overline{1.00} *$ & 1.00 & 0.63 & 0.35 \\
\hline 11 & $0.83^{* *}$ & 0.21 & $-0.84^{*}$ & $-0.83 *$ & $0.83^{*}$ & ${ }^{*} 0.53$ & -0.67 & 0.37 & 0.63 & $\overline{0.63}$ & 1.00 & -0.11 \\
\hline \multirow[t]{2}{*}{12} & -0.09 & -0.29 & 0.37 & -0.27 & -0.09 & 0.29 & 0.32 & 0.37 & 0.41 & 0.41 & $-\overline{0.11}$ & $\underline{1.00}$ \\
\hline & \multicolumn{12}{|c|}{ Spearman rank correlation } \\
\hline
\end{tabular}

* : significant $5 \%$ probability level; $* *$ : significant at $1 \%$ probability level

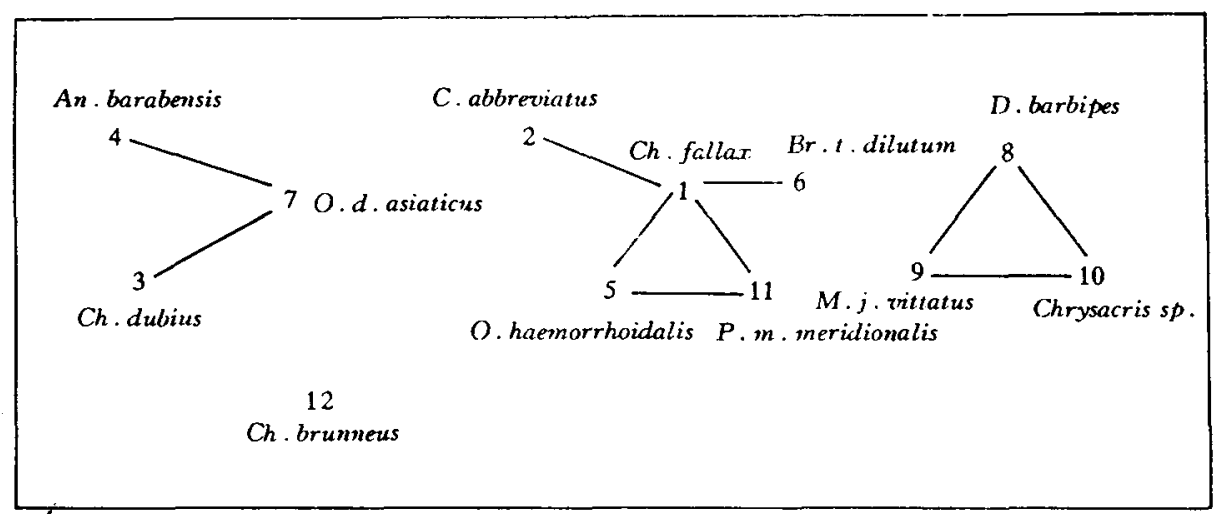

Fig. 1 Plexus diagram for twelve grasshopper species on ungrazed and overgrazed grasslands Note: Species connected by solid lines show positive correlation

The analyses of covariance compared a regression model that a common intercept and slope for the six grasshopper assemblages (Fig. 2). Species-area regressions for the six sites were highly significant for all grasshopper species (Size of area was significant at $P<0.05$ in all analyses of variance; see Fig. 2). The number of grasshopper species in all sites increased with samplng size. The 3 pair regression lines shown in Fig. 2 not only significantly differed 
from one another in slope, but also they differed markedly in intercept. The slope values ranged from 0.348 to 0.469 , the intercept from -0.153 to 0.057 . Generally, the greatest siope values ranged from 0.348 to 0.469 , the intercept from -0.153 to 0.057 . Generally, the greatest slope values for example were found in the grasshopper communities on ungrazed sites. The intercept value on the restored site of Aneurolepidium chinense steppe was significantly higher than that of overgrazed site, although the former slope value was slightly low. The intercept and slope estimates indicated that as sampling size increased, so more rapidly did the intercept and slope change on the ungrazed sites. The results imply that, given the same size of an area, the ungrazed sites may conserve more grasshopper species than overgrazed sites.

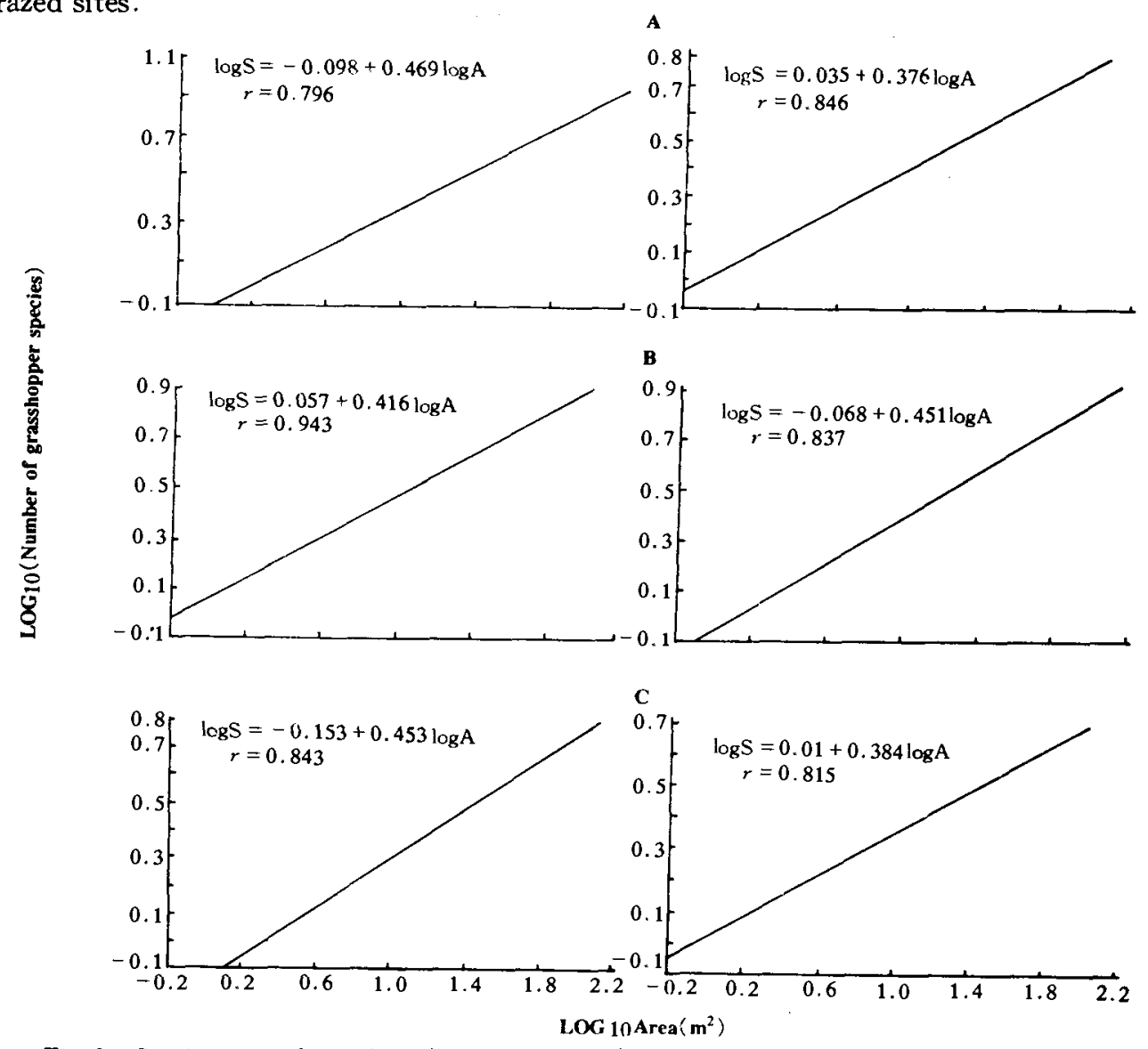

Fig. 2 Species-area relationships (logarithmic axes) for the number of grasshopper species on ungrazed (left) and overgrazed (right) steppes

A: Aneurolepidium chinense steppe: B: Stipa grandis steppe; C: Restored site (left) and degraded site ( right) of Aneurolepidium chinense steppe

The relationship of species number and their individual number was shown in Fig. 3 for the grasshopper found at ungrazed and overgrazed sites. The typical power function curves could be fund in the relationship of species-individual number on all sites. The results shown in Fig. 3 indicated that as individual number of grasshoppers increased, the increase of species number on overgrazed sites was much more rapidly than that on ungrazed sites, and quickly reached the peak value of the greatest species richness on the sites, although ungrazed sites maintained 
higher species richness. However, the species number on ungrazed sites gradually increased with the increase of the individual number, finally reached the peak value of species richness.
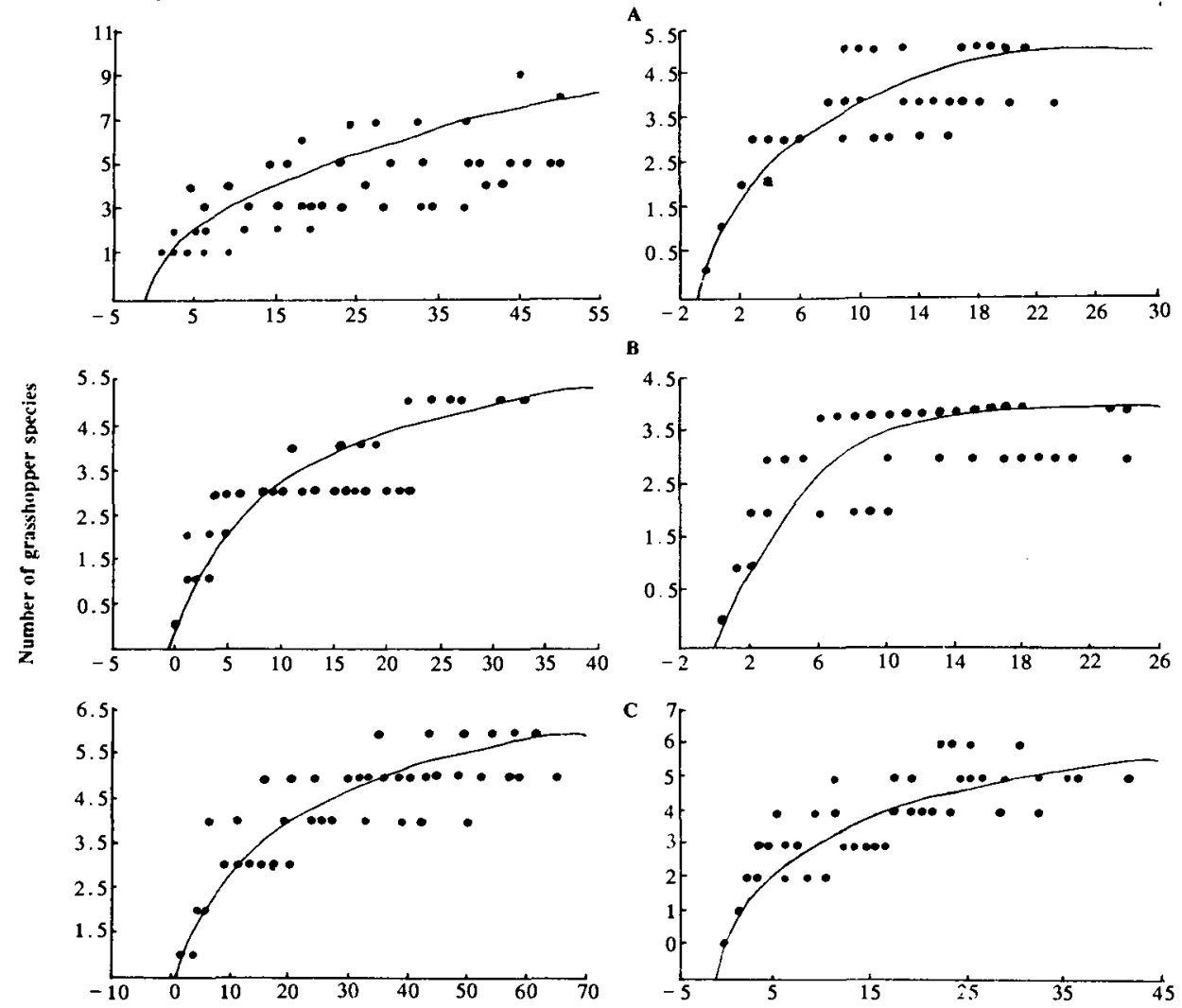

Number of grasshopper individuals

Fig. 3 Species-individual number relationships for all grasshoppers on ungrazed (left) and overgrazed (right) steppes

The site symbols are as in Fig. 2

\section{$4 \quad$ Conclusion and discussion}

The direct influence of overgrazing seems to simplify the species composition of grasshoppers, with a corresponding reduction in abundance, species richness and density. Thus, we may detect effect of grazing on the grassland environment based on the changes in grasshopper species and population fluctuation, as recorded by previous authors (Capinera and Sechrist 1982; Barker 1982; Kang 1994, 1995; Kang and Chen 1992, 1994). The results from diversity indices $\left(H^{\prime}\right)$ were not consistent with those of species richness $(S)$. The pattern was partially attributable to higher evenness of grasshoppers species on overgrazed grasslands, but their communities tended to have relatively simple organization and structure, dominated by the eurychoric and xerophytous species (Kang and Chen 1994).

The covariation analysis of grasshopper density indicated significant differences among grasshopper species in response to grazing and ungrazing regimes. The effect is not the same for 
all species, as has been pointed out by Kang and Chen (1992, 1994). The grasshopper species including $\mathrm{Ch}$. dubius, An. barabensis, $O$. decorus asiaticus with positive covariation are more abundant on overgrazed sites. By contrast, the population density including $\mathrm{Ch}$. fallax, $C$. abbreviatus and $O$. haemorrhoidalis with positive covariation are markedly reduced on overgrazed sites. On the other hand, the species that negatively responded to grazing seem to be the larger ones such as $\mathrm{Br}$. Tuberlatum dilutum and $P$. meridionalis meridiolalis. This could be because they are able to hide better from predators in areas of taller grass (Van Wingerden et al. 1991). The two species, M. japonicus vittatus and Chryacris sp., disappeared on overgrazed sites. The results mentioned above coincide with that of Kang and Chen (1992, 1994).

There were significant differences on the slope and interpretation of the species-area relationship between ungrazed and overgrazed grasslands, as indicated by the covariance analyses. It suggests that the slope estimate as a measure of isolation, immigration rates, or the propinquity of a large source pool may be confounded with habitat heterogeneity. The direct influence of grazing on the constants $C$ and $z$ of the species-area relationship provides a potential implication for conservation practice. Because of the greater slope $z$ values on ungrazed sites, ungrazed or lightly grazed sites accumulate species at a faster rate than do overgrazed sites. In addition, the species-individual relationship was markedly different between ungrazed and overgrazed sites. Species accumulation rate with grasshopper individual number was faster on overgrazed sites than on ungrazed sites, although ungrazed sites supported higher grasshopper density.

In summary, the implication of this analysis for conservation practice concerns the optimal design of nature reserves. Grasshopper community composition was different in ungrazd and grazed pastures. Some grasshopper species that are distributed on ungrazed sites disappear on grazed sites. Pickett and Thompson (1978) suggest that reserves should be designed and managed so that a maximum number of successional stages are represented. grasslands under different grazing intensities that show, on average, greater heterogeneity than the grassland with a single grazing practice, should contain more species. The influence of grazing practice on these species-area regressions suggests that grazing is an important determinant of species number and that it should not be ignored when considering strategies for grassland conservation.

\section{REFERENCES}

Anderson N L, 1964. Some relationships between grasshopper and vegetation. Ann. Ent. Soc. Amer., 57: $736 \sim 742$

Arrhenius O, 1921. Species and area. J. Ecol., 9:95 99

Barker J F, 1982. A preliminary study of the distribution of Acrididae in relation to overgrazing in Botswana. Botswana Notes and Rec., 14:1 10

Boecklen W J, N J Gotlli, 1984. Island biogeographic theory and conservation practice: species-area or speciesarea relationship? Biol. Conserv., 29:63 80

Boecklen W J, D Simberloff, 1986. Area-based extinction models in conservation. In: Elliott D (ed.), Dynamics of extinction, New York

Capinera J L, T S Sechist, 1982. Grasshopper (Acrididae)-Host plant asociations: response of grasshopper population to cattle grazing intensity. Can. Entomol., 22(1):71 81

Coleman B D, 1981. On random placement and species-area relations. Math. Biosci., 54:191 215

Connor E F, E D McCoy, 1979. The statistics and biology of the species-area relationship. Am. Nat., 113 : $791 \sim 833$

Diamond J M, R M may, 1976. Island biogeography and the design of nature reserves. In: May $R$ M (ed.), 
Theoretical ecology: principles and applications, Sunderland: Sinauer, $228 \sim 252$

Gilbert F S, 1980. The equilibrium theory of island biogeography: fact or fiction? J. Biogeogr., 7:209 235

Higgs A J, 1981. Island biogeographic theory and nature reserve design. J. Biogeogr., 8:117 124

Holmes N D, D S Smith, A Johnston, 1979. Effects of grazing by cattle on the abundance of grasshoppers on fescue grassland. J. Rang. Manag., 32:310 311

Isern-Vallverdu J, 1990. A quantitative ecology of Orthopteran communities on Pyrenean grasslands above timerline (Huesca, Spain). Bol. San. Verg. Plagas (Fuera deserie), 20:311 320

Jepson-Inne K, C E Bock, 1989. Response of grasshoppers (Orthoptera: Acrididae) to livestock grazing in southeastern Arizona: differences between seasonal and subfamily. Oecologia, 78:430 431

Joem A, 1982. Distribution, densities, and relative abundance of grasshopper (Orthoptera: Acrididae) in a Nebraska sandihills prairie. Southwest. Nat., 14:37 45

Kang L, Chen Y L, 1992. Temporal and spatial heterogeneity of grasshoppers. Res. Grass . Ecosys ., 4:109 123 (in Chinese)

Kang L, 1994. Influence of livestock grazing on grasshopper (Orthoptera: Acrididae) diversity in the Inner mongolian steppes. Chinese Biodiversity, 2(Suppl. ):9 17

Kang L, Chen Y L, 1994. Multidimensional analysis of resource utilization in assemblages of rangeland grasshoppers (Orthoptera: Acrididae). Entomol. Sinica, 1(3):264 282

Kang, 1995. Grasshopper-plant interactions under different grazing intensities in Inner Mongolia. Acta Ecol. Sinica, 15(1):37 47

Ludwig J A, J F Reynolds, 1988. Statistical ecology. John Wiley \& Sons, 337

MacArthur R H, 1965. pattern of species diversity. Biol. Rev., 40:510 533

MacArthur R H, E O Wilson, 1967. The theory of island biogeography. Princeton University Press

Miller R H, J A Onsager, 1991. Grasshopper (Orthoptera: Acrididae) and plant relationships under different grazing intensities. Environ. Entomol., 20(3):807 814

Pickett S T A, J N Thompson, 1978. Patch dynamics and the design of nature reserves. Biol. Conserv., 13: $27 \sim 37$

Preston F W, 1962. The canonical distribution of commonness and rarity. I. Ecology, 43:186 215

Quinn M A, D D Walgenbach, 1990. Influence of grazing history on the community structure of grasshoppers of a mixed-grass prairie. Environ. Entomol ., 19(6): 1756 1766

Samways M J, 1993. Insects in biodiversity conservation: some perspectives and directives. Biodiver. and Conserv., $2: 258 \sim 282$

Schoener T W, 1976. The species-area within archipelagoes: models and evidence from island landbirds. Proc. 16th Ornithol. Congr., Canberra: Australian Academy of Sciences, 629 642

Ter borgh J, 1974. Preservation of natural diversity: the problem of extinction-prone species. BioScience, 24: $715 \sim 722$

Usher M B, 1985. Implications of species-area relationships for wildlife conservation. J. Environ. Mgmt., 21 : $181 \sim 191$

Usher M B, 1991. Habitat structure and the design of nature reserves. In: Bell S S, E D McCoy, H R Mushinsky (eds.), Habitat Structure, the Physical Management of Objects in Space, New York: Chapman and Hall

Welch J L, R Redak, B C kondratieff, 1991. Effect of cattle grazing on the density and species of grasshoppers (Orthoptera:- Acrididae) of the Central Plains Experimental Range, Colorado: a reassessment after two decades. J. Kans. Ent. Soc., 64(3):337 343

Williams C B, 1964. Pattern in the balance of nature. New York: Academic Press

Wingerden W K, R E van, J C M Musters, R M J C Kleukers et al., 1991. The influence of cattle grazing on grasshopper abundance (Orthoptera: Acrididae). Proc. Exper. \& Appl. Entomol., 2:28 34 